\title{
Performance Study of a Four-Bed Silica Gel-Water Adsorption Chiller with the Passive Heat Recovery Scheme
}

\author{
Zhilong He, ${ }^{1}$ Xiaolin Wang, ${ }^{2}$ and Hui Tong Chua ${ }^{3}$ \\ ${ }^{1}$ School of Energy and Power Engineering, Xian Jiaotong University, 28 Xianning West Road, Xian 710049, China \\ ${ }^{2}$ School of Engineering \& ICT, University of Tasmania, Hobart, TAS 7001, Australia \\ ${ }^{3}$ School of Mechanical and Chemical Engineering, The University of Western Australia, 35 Stirling Highway, \\ Crawley, WA 6009, Australia
}

Correspondence should be addressed to Xiaolin Wang; xiaolin.wang@utas.edu.au

Received 23 August 2014; Accepted 19 October 2014

Academic Editor: Gongnan Xie

Copyright (C) 2015 Zhilong He et al. This is an open access article distributed under the Creative Commons Attribution License, which permits unrestricted use, distribution, and reproduction in any medium, provided the original work is properly cited.

\begin{abstract}
Adsorption chiller technology is one of the effective means to convert waste thermal energy into effective cooling, which substantially improves energy efficiency and lowers environmental pollution. This paper uses an improved lump-parameter design model to theoretically and experimentally evaluate the efficacy of the passive heat recovery scheme as applied to a four-bed adsorption chiller. Results show that the model can accurately track the experimental temporal system outlet temperatures. The performance predictions from this model compare favourably with experimental results. At rated temperature conditions and over a wide range of cycle times, both the cooling capacity and COP can be predicted to within $12.5 \%$. The analyses indicate that the model can be used confidently as a design tool for a four-bed adsorption chiller and the passive heat recovery scheme can effectively improve the system performance.
\end{abstract}

\section{Introduction}

In the past three decades, silica gel-water adsorption chillers have been proven to be an economically viable and environmentally friendly technology that can effectively convert low grade thermal energy to useful cooling [1-12]. In the standard form, this genre of adsorption chillers can be driven by any conceivable form of thermal energy with temperatures above $70^{\circ} \mathrm{C}$. By adopting a multibed and multistage design, the chiller can even be driven by $55^{\circ} \mathrm{C}$ thermal energy and produce reasonable cooling capacity at the expense of low COP $[5,9,13,14]$.

In order to improve the chiller performance, various technologies have been diligently pursued. GBU $\mathrm{mbH}[12]$ and Mayekawa Manufacturing Co. Ltd. applied the water circulation between the adsorber and desorber during switching in their commercial adsorption chillers. Wang [15] and Qu et al. [16] studied the combined heat and mass recovery in an adsorption cycle. Akahira et al. [17] investigated the effect of mass recovery on the chiller cooling capacity. Wang and
Chua [18] compared the passive heat recovery scheme and water circulation scheme as applied to a standard two-bed adsorption chiller. They concluded that both heat recovery schemes have the same efficacy in terms of performance improvement. However, in comparison to the water circulation scheme, the passive heat recovery scheme is much simpler in terms of the control system design and it eliminates the need of water valves to save the hardware cost. All these technologies significantly improved the conversion efficiency for a standard two-bed adsorption chiller. However, all of them were oblivious to the opportunity of maximizing enthalpy extraction from the low grade waste heat source and the issue of chilled water temperature fluctuation.

In the spirit of exploiting low grade waste heat sources and improving the energy conversion from waste heat to useful cooling, Saha et al. [13] studied a multistage silica gel-water adsorption chiller which could be operated by heat sources with temperatures as low as $55^{\circ} \mathrm{C}$ at the expense of very low COP. In the spirit of improving the energy conversion from waste heat to useful cooling, Chua et al. [14] proposed 


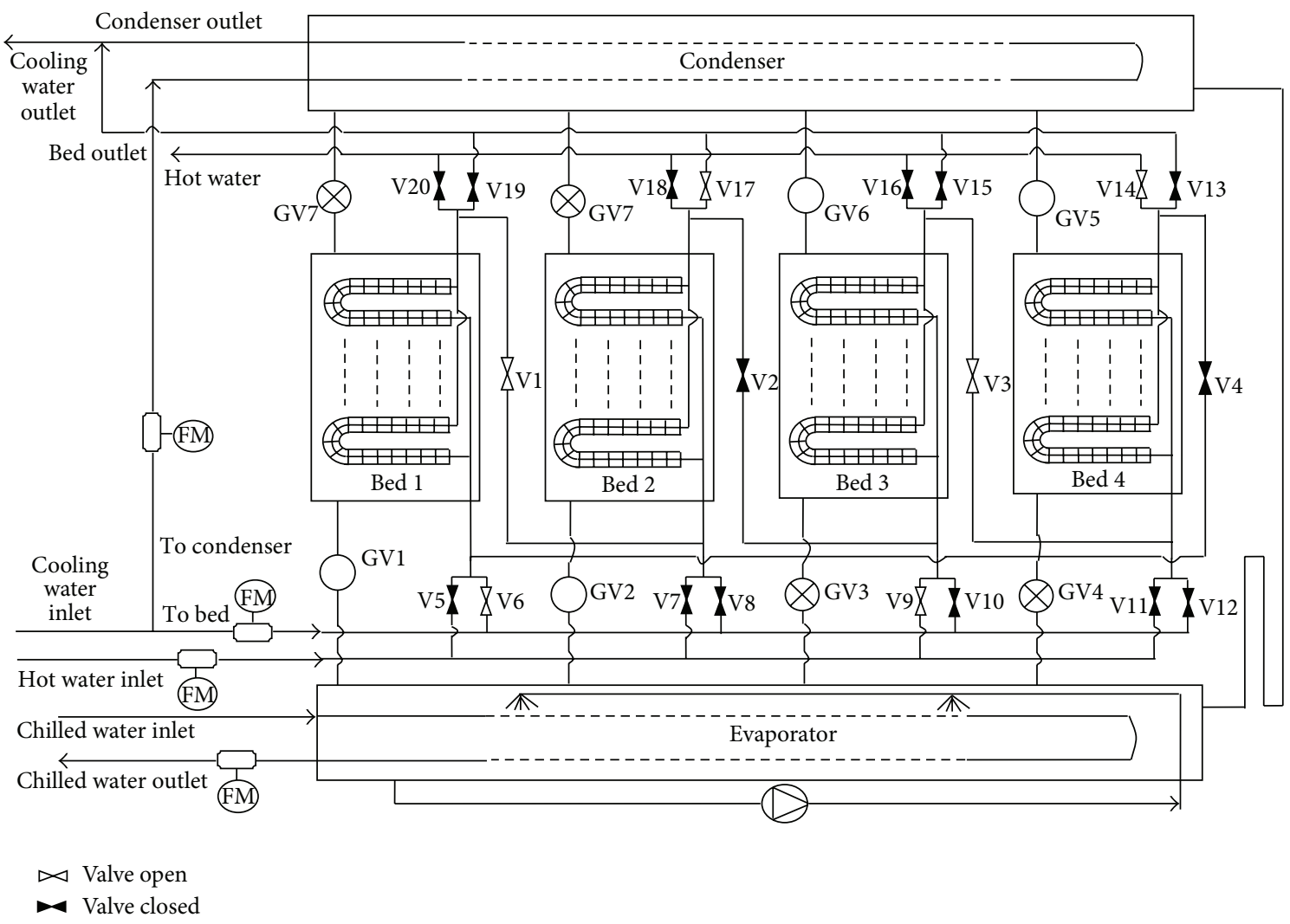

FIGURE 1: Schematic of a four-bed adsorption chiller adapted from [19].

a multibed regenerative adsorption scheme and demonstrated its efficacy theoretically. In comparison to a twobed adsorption chiller, they aimed to maximize the energy extraction from low grade thermal energy thereby maximizing the cooling capacity and concomitantly damp the chilled water outlet temperature fluctuation. Subsequently the four-bed adsorption chiller $[5,9,19]$ was successfully prototyped and validated the aforementioned virtues of fourbed chillers. However, the experimental study also revealed the inadequacies of previous model [14] which significantly overestimates the chiller coefficient of performance (COP). Furthermore, the experimental temperatures at the beds and system outlets showed that there are a big room for heat recovery from the hot water at system outlet.

The objective of this paper is to develop an improved lump-parameter model to analyse the performance of a fourbed adsorption chiller with the passive heat recovery scheme. We will demonstrate that this model can accurately predict the experimental temporal system outlet temperatures during the bed switching period. Specifically we will show that the simulation results agree favourably with experimental data over different operating conditions. Analyses show that the model can be reliably used for chiller design.

\section{Working Principle of a Four-Bed Adsorption Chiller with Its Passive Heat Recovery Scheme}

The detailed operating scheme of the standard four-bed adsorption chiller is described in $[14,19,20]$. The four-bed regenerative strategy is an extension from the standard twobed chiller operation. Briefly in the standard two-bed chiller, adsorption cycles require two processes: heating-desorptioncondensation and cooling-adsorption-evaporation. The former process requires energy to preheat the cold desorber and subsequently desorb water from the silica gel. The latter process demands energy removal from the precooling of the hot adsorber and the subsequent adsorption of water vapour onto silica gel. In the case of a four-bed chiller, one additional slave desorber and additional slave adsorber contribute to the desorption and adsorption processes, respectively. The operation of chiller is controlled so that a constant phase difference exists between the master and slave adsorbers and desorbers, respectively. The two processes in the operation cycle become heating-slave desorption-master desorption-condensation and cooling-slave adsorption-master adsorption-evaporation. The hot water flows through the master desorber and then into the slave desorber before being purged. Similarly the cooling water enters the master adsorber and then into the slave adsorber before returning to the cooling tower.

Figure 1 shows the schematic of a four-bed adsorption chiller [19]. Bed 1 works as the master adsorber and bed 2 the slave adsorber. Both adsorbers induce evaporation in the evaporator. Cooling water flows through bed 1 via valve 6 and then into bed 2 via valve 1 to sustain the adsorption in both beds. Meanwhile hot water flows through bed 3, which acts as the master desorber, via valve 9 and then into bed 4, which acts as the slave desorber, via valve 3 . Both desorbers 


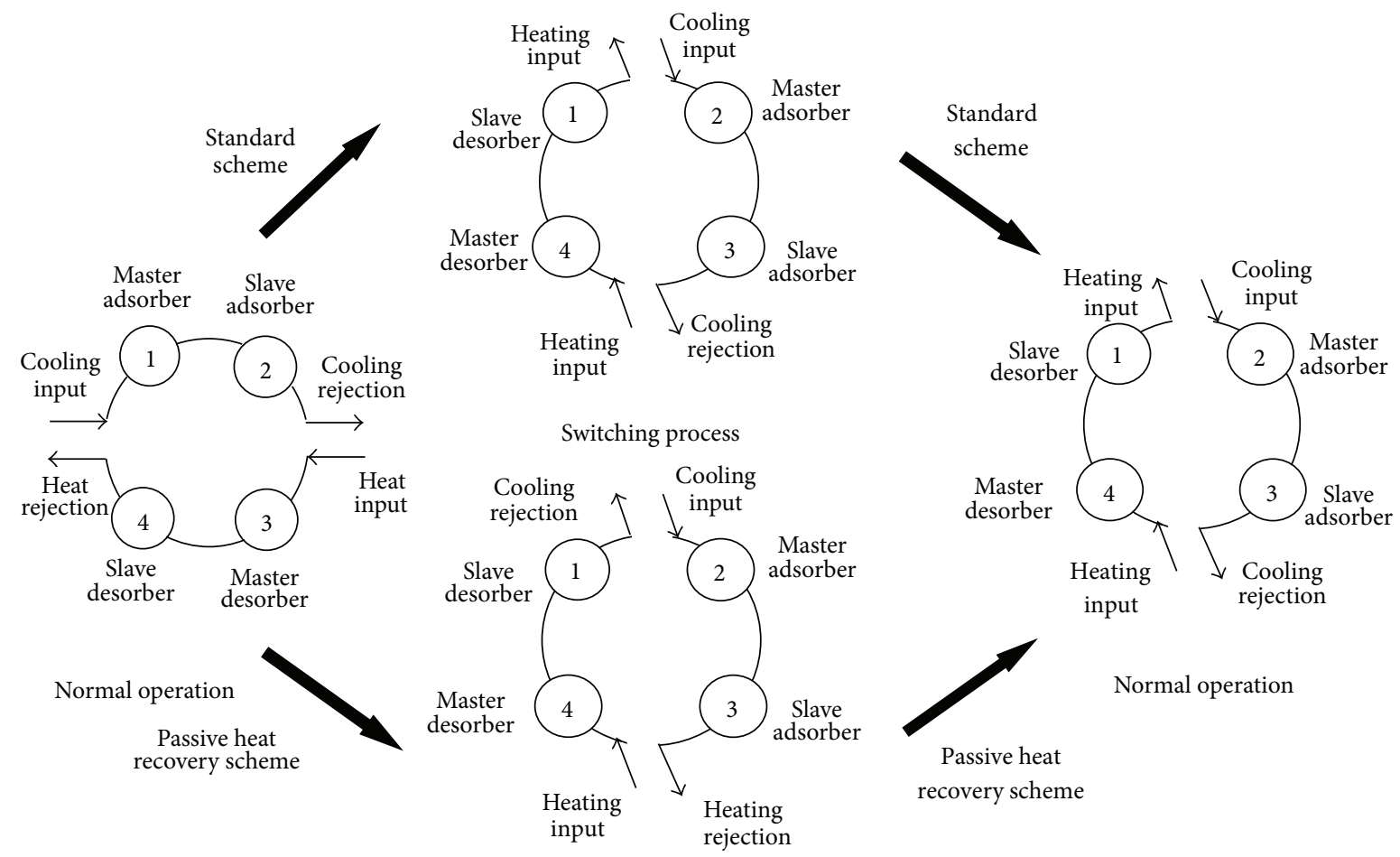

FIGURE 2: Schematic of the passive heat recovery scheme.

are connected to the condenser, which condenses the vapour stemming from the two desorbers, and the condensate eventually returns to the evaporator via a U-tube. This operating phase ends when the master adsorber is nearly saturated and the master desorber is sufficiently purged of water vapour. In the ensuing switching phase, bed 1 changes to a slave desorber, bed 2 to a master adsorber, bed 3 to a slave adsorber, and bed 4 to a master desorber. Beds 2 and 4 are connected to the evaporator and condenser, respectively. During this period, due to the resident cooling water in the heat exchanger and its inherent thermal mass, bed 1 must be preheated. Similarly bed 3 must be precooled because of the resident hot water and its inherent thermal mass. To prevent parasitic vapour migration, beds 1 and 3 are isolated from both the evaporator and condenser. The total energy input $Q_{\text {input }}$ to the chiller includes both the preheating energy $Q_{p-h}$ during switching period to preheat the cool desorber and energy input $Q_{\text {hot }}$ into both the master and slave desorbers during normal operation to sustain the desorption. The total energy rejection $Q_{\text {rej }}$ comprises both the precooling energy $Q_{p-c}$ to precool the hot adsorber and the energy rejection $Q_{c}$ from both the master and slave adsorbers during normal adsorption process to sustain the adsorption.

The passive heat recovery scheme has been described in $[18,19]$. It aims to recover the energy $Q_{\text {rec }}$ from the energy $Q_{p-c}$ to compensate for the energy $Q_{p-h}$ by always channelling the water from the hot adsorber to the heat source and water from the cool desorber to the cooling tower during the switching period. Figure 2 schematically demonstrates the passive heat recovery scheme. During the switching period, the cooling water upon passing through the hot adsorber is heated and directed to the heat source instead of to the cooling tower by delaying the switching of valves V16 and V19, respectively, as in Figure 1. Concomitantly, the incoming hot water upon heating up the cool desorber is thereby cooled and directed to the cooling tower. This process terminates when the hot water outlet temperature equals the cooling water outlet temperature. With this water circulation scheme, a portion of the otherwise rejected precooling energy $Q_{p-c}$ is recovered $\left(Q_{\text {rev }}\right)$ and returned to the heat source. Hence the passive heat recovery scheme attenuates the energy input to the chiller system and improves the COP.

\section{Mathematical Modelling}

The mathematical model is an improvement of our previous research work $[14,21]$. The equations for adsorption beds are adapted from these two literatures and the equations for the connection piping system are built based on the mass and energy balance. The major assumptions are listed below.

(1) In the adsorbers and desorbers, the temperature of silica gel, water and heat exchanger materials including fins, tubes, and supporting frames are approximated by a representative temperature.

(2) The cooling, heating, and chilled water in the heat exchanger tubes and connection pipes are discretized into a number of elements to capture the thermal wave propagation during the bed switching period.

(3) In the condenser, the tube bank surface is assumed to be able to hold a certain maximum amount of 
condensate, $M_{\text {ref,cond }}^{\mathrm{Max}}$. Beyond this the condensate would flow into the evaporator via the U-tube.

(4) The system outlet is about $1 \mathrm{~m}$ away from the beds' outlet according to the commercial adsorption chiller design.

3.1. Rate of Adsorption and Desorption. The rate of adsorption or desorption is calculated by the linear driving force kinetic equation:

$$
\frac{d q}{d t}=15 \frac{D_{s o} e^{-E_{a} /(R T)}}{R_{p}^{2}}\left(q^{*}-q\right) .
$$

All the coefficients were determined by Chihara and Suzuki [20] and $q^{*}$ is available as a Henry's law correlation [14] underpinned by manufacturer's proprietary data [22]:

$$
q^{*}=K_{o} \exp \left(\frac{-\Delta H_{\mathrm{ads}}}{R T}\right) P
$$

where $K_{o}=2 \times 10^{-12} \mathrm{~Pa}^{-1}$ and $\Delta H_{\mathrm{ads}}=2.51 \times 10^{3} \mathrm{~kJ} / \mathrm{kg}$.

3.2. Energy Balance in the Adsorbers and Desorbers. The energy balance for the adsorber during its interaction with the evaporator during normal operation can be described as

$$
\begin{aligned}
&\left(M_{\mathrm{sg}} c_{v, \mathrm{sg}}\right.\left.+M_{\mathrm{Hex}} c_{v, \mathrm{Hex}}+M_{\mathrm{sg}} q_{\mathrm{bed}, i} c_{v g}\right) \frac{d T_{\mathrm{bed}, i}}{d t} \\
&= M_{\mathrm{sg}} \frac{d q_{\mathrm{bed}, i}}{d t} \\
& \quad \times\left\{\zeta\left[h_{g}\left(T_{\text {evap }}\right)-h_{g}\left(P_{\text {evap }}, T_{\mathrm{bed}, i}\right)+\Delta H_{\mathrm{ads}}\right]\right. \\
&\left.\quad+(1-\zeta) \Delta H_{\mathrm{ads}}\right\}-U_{c} \frac{A_{\mathrm{bed}}}{N} \sum_{k=1}^{N}\left(T_{\mathrm{bed}, i}-T_{k, i}\right)
\end{aligned}
$$

and the energy balance for the cooling water in the adsorber is expressed as

$$
\begin{aligned}
& \rho_{f} \mathcal{c}_{v f} \frac{V_{\mathrm{bed}, i}}{N} \frac{d T_{k, i}}{d t} \\
& \quad=\dot{m}_{\text {cool }}\left[h_{f}\left(T_{k-1, i}\right)-h_{f}\left(T_{k, i}\right)\right]+U_{c} \frac{A_{\text {bed }, i}}{N}\left(T_{\text {bed }, i}-T_{k, i}\right),
\end{aligned}
$$

where $i$ represents an adsorber, $i=1$ means master adsorber and $i=2$ means slave absorber, and $k$ represents the local element ranging from 1 to $N$.
The energy balance for the desorber during its interaction with the condenser during normal operation is expressed as

$$
\begin{aligned}
& \left(M_{\mathrm{sg}} c_{v, \mathrm{sg}}+M_{\mathrm{Hex}} c_{v, \text { Hex }}+M_{\mathrm{sg}} q_{\mathrm{bed}, j} c_{v g}\right) \frac{d T_{\text {bed }, j}}{d t} \\
& =M_{\mathrm{sg}} \frac{d q_{\mathrm{bed}, j}}{d t} \\
& \quad \times\left\{\zeta\left[h_{g}\left(T_{\text {cond }}\right)-h_{g}\left(P_{\text {cond }}, T_{\text {bed }, j}\right)+\Delta H_{\text {ads }}\right]\right. \\
& \left.\quad+(1-\zeta) \Delta H_{\text {ads }}\right\}-U_{h} \frac{A_{\text {bed }, j}}{N} \sum_{k=1}^{N}\left(T_{\text {bed }, j}-T_{k, j}\right)
\end{aligned}
$$

and the energy balance for the hot water in the desorber is described as

$$
\begin{aligned}
\rho_{f} \mathcal{c}_{v f} & \frac{V_{\text {bed }, j}}{N} \frac{d T_{k, j}}{d t} \\
= & \dot{m}_{\text {hot }}\left[h_{f}\left(T_{k-1, j}\right)-h_{f}\left(T_{k, j}\right)\right] \\
& +U_{h} \frac{A_{\text {bed }, j}}{N}\left(T_{\text {bed }, j}-T_{k, j}\right),
\end{aligned}
$$

where $\zeta=1$ if $q^{*}>q$ and $\zeta=0$ if $q^{*}<q . j$ represents a desorber. $j=3$ means master desorber and $j=4$ means slave desorber. $k$ represents the local element ranging from 1 to $N$.

During the switching period, the slave adsorber and desorber become the master adsorber and desorber, respectively. Their energy balances are expressed in (3)-(6). At the same time, the master adsorber becomes the slave desorber and the master desorber becomes the slave adsorber. Accordingly, the gas valves between the current slave desorber and condenser and between the current slave adsorber and evaporator are shut and the volume inside those two adsorbent beds is constant. For these two adsorbent beds, the energy balance equation for the beds and the interacting fluids can be written as

$$
\begin{aligned}
& \left(M_{\mathrm{sg}} \mathcal{c}_{v, \mathrm{sg}}+M_{\mathrm{Hex}} c_{v, \mathrm{Hex}}+M_{\mathrm{sg}} q_{\mathrm{bed}, l} c_{v g}\right) \frac{d T_{\mathrm{bed}, l}}{d t} \\
& =-U_{h / c} \frac{A_{\mathrm{bed}}}{N} \sum_{k=1}^{N}\left(T_{\mathrm{bed}, l}-T_{k, l}\right), \\
& \rho_{f} \mathcal{c}_{v f} \frac{V_{\mathrm{bed}}}{N} \frac{d T_{k, l}}{d t} \\
& =\dot{m}_{\text {cool } / \text { hot }}\left[h_{f}\left(T_{k-1, l}\right)-h_{f}\left(T_{k, l}\right)\right] \\
& +U_{h / c} \frac{A_{\mathrm{bed}}}{N}\left(T_{\text {bed }, l}-T_{k, l}\right),
\end{aligned}
$$

where $l=2$ refers to the hot slave adsorber and $l=4$ to the cold slave desorber. $k$ ranges from 1 to $N$. 
The connecting pipes between the beds are utilised when the cooling (heating) fluid is directed from the master adsorber (desorber) to the slave adsorber (desorber). This then impacts on the temperature of the fluid in the slave adsorber (desorber), due to heat loss from the fluid while travelling through the pipes. The energy balances for the connecting pipes are expressed below:

$$
\begin{aligned}
& \rho_{f} \frac{V_{f}}{N_{\text {tube }}} c_{v, f} \frac{d T_{k, i / j, m}}{d t} \\
&= \delta \dot{m}_{\text {cool } / \text { hot }}\left[h_{f}\left(T_{k-1, i / j, m}\right)-h_{f}\left(T_{k, i / j, m}\right)\right] \\
&+\hbar \frac{A_{m, \text { tube }}}{N_{\text {tube }}}\left(T_{m, k}-T_{k, i / j, m}\right), \\
& \rho_{m} \frac{V_{m}}{N_{\text {tube }}} c_{v, m} \frac{d T_{m, k}}{d t} \\
&=\hbar_{m, f} \frac{A_{m, \text { tube }}}{N_{\text {tube }}}\left(T_{k, i / j, m}-T_{m, k}\right) \\
& \quad+\hbar_{m, \text { air }} \frac{A_{\text {air,tube }}}{N_{\text {tube }}}\left(T_{\text {air }, k}-T_{m, k}\right) \\
& \quad+k_{m}\left(T_{m, k-1}-2 T_{m, k}+T_{m, k+1}\right) \frac{N A_{\text {cross,tube }}}{L},
\end{aligned}
$$

where $\delta$ is defined as $\delta=1$ for connecting pipes between master adsorber and slave adsorber, and between master desorber and slave desorber; $\delta=0$ for connecting pipes between slave adsorber and master desorber, and between slave desorber and master adsorber. The subscript $m$ highlights that we are referring to the connecting pipes between beds, and $k$ ranges from $N+1$ to $N+N_{\text {tube }}$.

The initial conditions for the adsorbers, desorbers, and connecting pipes are expressed as follows.

For the adsorbers: $T_{0, i}(0)=T_{k, i}(0)=T_{\text {cool }}^{\text {in }}, k=1$ to $N$; $T_{\text {bed }, i}(0)=T_{\text {cool }}^{\text {in }} ; q_{\text {bed }, i}(0)=q_{\text {bed }, i}^{\text {in }} ; P_{\text {evap }}(0)=P_{\text {sat }}\left(T_{\text {chilled }}^{\text {in }}\right) ;$ $T_{\text {evap }}(0)=T_{\text {chilled }}^{\text {in }}$.

For the desorbers: $T_{0, j}(0)=T_{k, j}(0)=T_{\text {hot }}^{\text {in }}, k=1$ to $N$; $T_{\text {bed }, j}(0)=T_{\text {hot }}^{\text {in }} ; q_{\text {bed }, j}(0)=q_{\text {bed }, j}^{\text {in }} ; P_{\text {cond }}(0)=P_{\text {sat }}\left(T_{\text {cool }}^{\text {in }}\right) ;$ $T_{\text {cond }}(0)=T_{\text {cool }}^{\text {in }}$.

For the connecting pipes, $T_{k, i, m}(0)=T_{\text {cool }}^{\text {in }}$ and $T_{k, j, m}(0)=$ $T_{\text {hot }}^{\text {in }}, k=N+1$ to $N+N_{\text {tube }}$. The corresponding piping materials will have the same initial conditions as the water contained therein.

The boundary conditions for the adsorbers and desorbers are expressed as follows.

During normal operation: for the master and slave adsorbers: $T_{0,1}(t)=T_{\text {cool }}^{\text {in }} ; T_{0,2}(t)=T_{N+N_{\text {tube }}, 1, m}(t)$, and for desorbers: $T_{0,3}(t)=T_{\text {hot }}^{\text {in }} ; T_{0,4}(t)=T_{N+N_{\text {tube }}, 3, m}(t)$.

During the switching operation, following from the normal operation described immediately above: for the master and slave adsorbers: $T_{0,2}(t)=T_{\text {cool }}^{\text {in }} ; T_{0,3}(t)=T_{N+N_{\text {tube }}, 2, m}(t)$, and for desorbers: $T_{0,4}(t)=T_{\text {hot }}^{\text {in }} ; T_{0,1}(t)=T_{N+N_{\text {tube }}, 4, m}(t)$.

The temperatures at the system outlet differ from those at the bed outlet due to the connection piping. The corresponding amount of resident water and piping material are separately considered as lumped systems. For the standard operation scheme, the temperatures at the system outlet can be determined by

$$
\begin{aligned}
& \rho_{f} V_{f, \text { cool }} c_{v, f} \frac{d T_{\text {cool,out }}}{d t} \\
& =\dot{m}_{\text {cool }}\left[h_{f}\left(T_{N, 2}\right)-h_{f}\left(T_{\text {cool,out }}\right)\right] \\
& +\hbar\left(T_{\text {pm,cool }}-T_{\text {cool,out }}\right) A_{\text {pm,tube }}, \\
& \rho_{\mathrm{pm}} V_{\mathrm{pm}} \mathcal{c}_{v, \mathrm{pm}} \frac{d T_{\mathrm{pm}, \text { cool }}}{d t} \\
& =\hbar_{\mathrm{pm}, f}\left(T_{\text {cool,out }}-T_{\mathrm{pm}, \text { cool }}\right) A_{\mathrm{pm}, \text { tube }} \\
& +\hbar_{\mathrm{pm}, \text { air }}\left(T_{\text {air }}-T_{\mathrm{pm}, \text { cool }}\right) A_{\text {air,tube }} \\
& \rho_{f} V_{f, \text { hot }} c_{v, f} \frac{d T_{\text {hot,out }}}{d t} \\
& =\dot{m}_{\text {hot }}\left[h_{f}\left(T_{N, 4}\right)-h_{f}\left(T_{\text {hot,out }}\right)\right] \\
& +\hbar\left(T_{\text {pm,hot }}-T_{\text {hot,out }}\right) A_{\text {pm,tube }}, \\
& \rho_{\mathrm{pm}} V_{\mathrm{pm}} c_{v, \mathrm{pm}} \frac{d T_{\mathrm{pm}, \mathrm{hot}}}{d t} \\
& =\hbar_{\mathrm{pm}, f}\left(T_{\text {hot,out }}-T_{\mathrm{pm}, \text { hot }}\right) A_{\mathrm{pm}, \text { tube }} \\
& +\hbar_{\mathrm{pm} \text {,air }}\left(T_{\text {air }}-T_{\mathrm{pm}, \text { hot }}\right) A_{\text {air,tube }} .
\end{aligned}
$$

The initial conditions for the temperatures are $T_{\text {cool,out }}(0)=$ $T_{m, \text { cool }}(0)=T_{\text {cool }}^{\text {in }}, T_{\text {hot, out }}(0)=T_{m \text {,hot }}(0)=T_{\text {hot }}^{\text {in }}$.

For the passive heat recovery scheme, the system outlet temperatures depend on the outlet temperatures at the slave desorber and adsorber during the switching period. If $T_{N, 2} \geq$ $T_{N, 4}$ then we assign $T_{\text {switch,cool }}=T_{N, 4}$ and $T_{\text {switch,hot }}=T_{N, 2}$; if $T_{N, 2}<T_{N, 4}$ then $T_{\text {switch,cool }}=T_{N, 2}$ and $T_{\text {switch,hot }}=$ $T_{N, 4}$. The system outlet temperatures can then be accordingly determined as

$$
\begin{aligned}
\rho_{f} V_{f, \text { cool }} c_{v, f} \frac{d T_{\text {cool,out }}}{d t} \\
=\dot{m}_{\text {cool }}\left[h_{f}\left(T_{\text {switch,cool }}\right)-h_{f}\left(T_{\text {cool,out }}\right)\right] \\
+\hbar\left(T_{\text {pm,cool }}-T_{\text {cool,out }}\right) A_{\text {pm,tube }}
\end{aligned}
$$




$$
\begin{aligned}
& \rho_{\mathrm{pm}} V_{\mathrm{pm}} c_{v, \mathrm{pm}} \frac{d T_{\mathrm{pm}, \mathrm{cool}}}{d t} \\
& =\hbar_{m, f}\left(T_{\text {cool,out }}-T_{\text {pm,cool }}\right) A_{\text {pm,tube }} \\
& +\hbar_{m \text {,air }}\left(T_{\text {air }}-T_{\text {pm,cool }}\right) A_{\text {air,tube }} \\
& \rho_{f} V_{f, \text { hot }} c_{v, f} \frac{d T_{\text {hot,out }}}{d t} \\
& =\dot{m}_{\text {hot }}\left[h_{f}\left(T_{\text {switch,hot }}\right)-h_{f}\left(T_{\text {hot,out }}\right)\right] \\
& +\hbar\left(T_{\text {pm,hot }}-T_{\text {hot,out }}\right) A_{\text {pm,tube }} \text {. } \\
& \rho_{\mathrm{pm}} V_{\mathrm{pm}} c_{v, \mathrm{pm}} \frac{d T_{\mathrm{pm}, \mathrm{hot}}}{d t} \\
& =\hbar_{\mathrm{pm}, f}\left(T_{\text {hot,out }}-T_{\mathrm{pm}, \text { hot }}\right) A_{\mathrm{pm}, \text { tube }} \\
& +\hbar_{\mathrm{pm}, \text { air }}\left(T_{\text {air }}-T_{\text {pm,hot }}\right) A_{\text {air.tube }} \text {. }
\end{aligned}
$$

The initial conditions for the temperatures are similarly assigned as $T_{\text {cool,out }}(0)=T_{m, \text { cool }}(0)=T_{\text {cool }}^{\text {in }}, T_{\text {hot,out }}(0)=$ $T_{m \text { hot }}(0)=T_{\text {hot }}^{\text {in }}$.

3.3. Energy Balance for the Condenser. The energy balance for the condenser and the cooling water inside the condenser is expressed as

$$
\begin{aligned}
& \left(M_{\text {ref,cond }} c_{v f}\left(T_{\text {cond }}\right)+M_{\text {cond }} c_{v, \text { cond }}\right) \frac{d T_{\text {cond }}}{d t} \\
& \quad+\sum \theta_{j} h_{f}\left(T_{\text {cond }}\right) M_{\text {sg }} \frac{d q_{\text {bed }, j}}{d t} \\
& =-\sum M_{\text {sg }} \frac{d q_{\text {bed }, j}}{d t}\left[\zeta h_{g}\left(T_{\text {cond }}\right)+(1-\zeta) h_{g}\left(P_{\text {cond }}, T_{\text {bed }, j}\right)\right. \\
& \quad-U_{\text {cond }} \frac{A_{\text {cond }}}{N_{2}} \sum_{k=1}^{N_{2}}\left(T_{\text {cond }}-T_{k, \text { cond }}\right), \\
& \rho_{f} \mathcal{c}_{v f} \frac{V_{\text {cond }}}{N_{2}} \frac{d T_{k, \text { cond }}}{d t} \\
& =\dot{m}_{\text {cond }}\left[h_{f}\left(T_{k-1, \text { cond }}\right)-h_{f}\left(T_{k, \text { cond }}\right)\right] \\
& +U_{\text {cond }} \frac{A_{\text {cond }}}{N_{2}}\left(T_{\text {cond }}-T_{k, \text { cond }}\right),
\end{aligned}
$$

where $\theta_{j}$ is defined as

$$
\begin{aligned}
& \theta_{j}=1 \text { when } M_{\text {ref,cond }}<M_{\text {ref,cond }}^{\max } ; \theta_{j}=1 \text { when } \\
& M_{\text {ref,cond }}=M_{\text {ref,cond }}^{\max } \text { and } d q_{\mathrm{bed}, j} / d t>0 ; \\
& \theta_{j}=0 \text { when } M_{\text {ref,cond }}=M_{\text {ref,cond }}^{\max } \text { and } d q_{\text {bed, }, j} / d t<0 .
\end{aligned}
$$

The boundary and initial conditions are

$$
\begin{gathered}
T_{0, \text { cond }}(t)=T_{\text {cool }}^{\text {in }} ; \quad T_{k, \text { cond }}(0)=T_{\text {cool }}^{\text {in }}, \quad k=1 \text { to } N_{2} ; \\
T_{\text {cond }}(0)=T_{\text {cool }}^{\text {in }} ; \quad q_{\text {bed }, j}(0)=q_{\text {bed }, j}^{\text {in }} ; \\
M_{\text {ref,cond }}(0)=M_{\text {ref,cond }}^{\max }
\end{gathered}
$$

3.4. Energy Balance for the Evaporator. The energy balance for the evaporator and the chilled water inside the evaporator is expressed as

$$
\begin{aligned}
\left(M_{\text {ref,evap }} c_{v f}+M_{\text {evap }} c_{v, \text { evap }}\right) \frac{d T_{\text {evap }}}{d t}-h_{f}\left(T_{\text {evap }}\right) \sum_{l=1}^{2} \gamma_{l} \frac{d q_{\text {bed }, l}}{d t} \\
=-(1-\zeta)(1-\theta) h_{f}\left(T_{\text {cond }}\right) M_{\text {sg }} \sum \frac{d q_{\text {bed }, j}}{d t} \\
\quad-M_{\text {sg }} \sum \frac{d q_{\text {bed }, i}}{d t}\left[\zeta h_{g}\left(T_{\text {evap }}\right)+(1-\zeta) h_{g}\left(P_{\text {evap }}, T_{\text {bed }, i}\right)\right] \\
\quad-U_{\text {chilled }} \frac{A_{\text {evap }}}{N_{1}} \sum_{k=1}^{N_{1}}\left(T_{\text {evap }}-T_{k, \text { evap }}\right), \\
\rho_{f} \mathcal{c}_{v f} \frac{V_{\text {evap }} \frac{d T_{k, \text { evap }}}{d t}}{N_{1}} \\
=\dot{m}_{\text {chilled }}\left[h_{f}\left(T_{k-1, \text { evap }}\right)-h_{f}\left(T_{k, \text { evap }}\right)\right] \\
\quad+U_{\text {chilled }} \frac{A_{\text {evap }}}{N_{1}}\left(T_{\text {evap }}-T_{k, \text { evap }}\right),
\end{aligned}
$$

where $\gamma=1$ when the bed interacts with the evaporator and $\gamma=(1-\zeta)(1-\theta)$ when the bed interacts with the condenser. The boundary and initial conditions are

$$
\begin{gathered}
T_{0, \text { evap }}(t)=T_{\text {chilled }}^{\text {in }} \\
T_{k \text {,evap }}(0)=T_{\text {chilled }}^{\text {in }}, \quad k=1 \text { to } N_{1} ; \\
T_{\text {evap }}(0)=T_{\text {chilled }}^{\text {in }} ; \quad q_{\text {bed }, j}(0)=q_{\text {bed }, j}^{\text {in }} ; \\
q_{\text {bed }, i}(0)=q_{\text {bed }, i}^{\text {in }} .
\end{gathered}
$$

The cycle average cooling capacity $Q_{\text {evap }}$, energy input $Q_{\text {hot }}$, and COP are, respectively, calculated as

$$
Q_{\text {evap }}=\dot{m}_{\text {chilled }} c_{v f} \int_{0}^{t_{\text {cycle }}} \frac{T_{\text {chilled }}^{\text {in }}-T_{\text {chilled }}^{\text {out }}}{t_{\text {cycle }}} d t \text {, }
$$

$$
\begin{gathered}
Q_{\text {hot }}=\dot{m}_{\text {heat }} c_{v f} \int_{0}^{t_{\text {cycle }}} \frac{T_{\text {hot }}^{\text {in }}-T_{\text {hot }}^{\text {out }}}{t_{\text {cycle }}} d t, \\
\operatorname{COP}=\frac{Q_{\text {evap }}}{Q_{\text {hot }}} .
\end{gathered}
$$


TABLE 1: Values for the parameters used in the present model.

\begin{tabular}{|c|c|}
\hline$D_{\text {so }}$ & $2.54 \times 10^{-4} \mathrm{~m}^{2} / \mathrm{s}$ \\
\hline$E_{a}$ & $4.2 \times 10^{4} \mathrm{~J} / \mathrm{mol}$ \\
\hline$R_{p}$ & $1.7 \times 10^{-4} \mathrm{~m}$ \\
\hline$U_{\text {bed }}$ & $1002 \mathrm{~W} / \mathrm{m}^{2} \cdot \mathrm{K}$ \\
\hline$U_{\text {cond }}$ & $5833 \mathrm{~W} / \mathrm{m}^{2} \cdot \mathrm{K}$ \\
\hline$U_{\text {chilled }}$ & $3028 \mathrm{~W} / \mathrm{m}^{2} \cdot \mathrm{K}$ \\
\hline$A_{\text {bed }}$ & $2.7 \mathrm{~m}^{2}$ \\
\hline$A_{\text {cond }}$ & $5.08 \mathrm{~m}^{2}$ \\
\hline$A_{\text {evap }}$ & $3.53 \mathrm{~m}^{2}$ \\
\hline$A_{\text {cham }}$ & $7.1 \mathrm{~m}^{2}$ \\
\hline$c_{p, \mathrm{Al}}$ & $905 \mathrm{~J} / \mathrm{kg} \cdot \mathrm{K}$ \\
\hline$c_{p, \mathrm{Cu}}$ & $386 \mathrm{~J} / \mathrm{kg} \cdot \mathrm{K}$ \\
\hline$c_{p, \mathrm{sg}}$ & $924 \mathrm{~J} / \mathrm{kg} \cdot \mathrm{K}$ \\
\hline$M_{\mathrm{sg}}$ & $36 \mathrm{~kg}$ \\
\hline$M_{\text {bed }}$ & $40 \mathrm{~kg}$ \\
\hline$M_{\text {fin }}$ & $21 \mathrm{~kg}$ \\
\hline$M_{\text {cond }}$ & $26 \mathrm{~kg}$ \\
\hline$M_{\text {evap }}$ & $13.6 \mathrm{~kg}$ \\
\hline$M_{\text {water }}$ & $57 \mathrm{~kg}$ \\
\hline$\hbar_{m, \text { air }}$ & $10 \mathrm{~W} / \mathrm{m}^{2} \cdot \mathrm{K}$ \\
\hline$k_{m}$ & $401 \mathrm{~W} / \mathrm{m} \cdot \mathrm{K}$ \\
\hline$\dot{m}_{\text {cool }}$ & $48 \mathrm{~L} / \mathrm{min}$ \\
\hline$\dot{m}_{\text {hot }}$ & $48 \mathrm{~L} / \mathrm{min}$ \\
\hline$\dot{m}_{\text {cond }}$ & $120 \mathrm{~L} / \mathrm{min}$ \\
\hline$\dot{m}_{\text {chilled }}$ & $48 \mathrm{~L} / \mathrm{min}$ \\
\hline
\end{tabular}

\section{Results and Discussion}

The investigations described herein are conducted on a fourbed adsorption chiller [19]. The values for the parameters used in the present model are furnished in Table 1. The simulation results are compared with the experimental results reported in our previous papers $[9,19]$ at the various working conditions. The rated operating temperature conditions follow the convention stipulated in the ARI standard. The hot water temperature is $85^{\circ} \mathrm{C}$ while the cooling and chilled water temperatures are $29.4^{\circ} \mathrm{C}$ and $12.2^{\circ} \mathrm{C}$, respectively.

The water temperatures at the outlets of the condenser, evaporator, and bed systems are commonly used to characterize the adsorption/desorption behaviour. Figure 3 shows typical temperature histories at the outlets of the four-bed adsorption chiller system with the passive heat recovery at rated temperature conditions with a cycle time $320 \mathrm{~s}$. It compares the predicted simulation results and experimental data published in our previous paper [19]. The result indicates that our present simulation results exhibit a sufficiently good agreement with the experimental data. Figure 4 presents the temperature histories at the outlets of both condenser and evaporator. Again it displays a good agreement with the experimental data. It is palpable that our model accurately describes the workings of the passive heat recovery scheme.

Figures 5 and 6 show the system performance at different cycle times, with simulations benchmarked against experimental data $[9,19]$. Since the passive heat recovery scheme

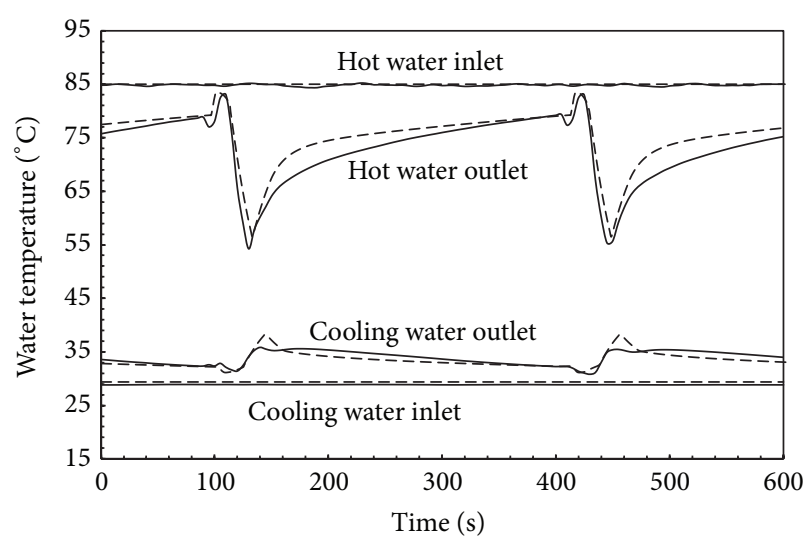

FIGURE 3: A comparison of the system temporal temperature profiles between experiment and simulations under passive heat recovery scheme. - : experimental data; - - -: simulation results.

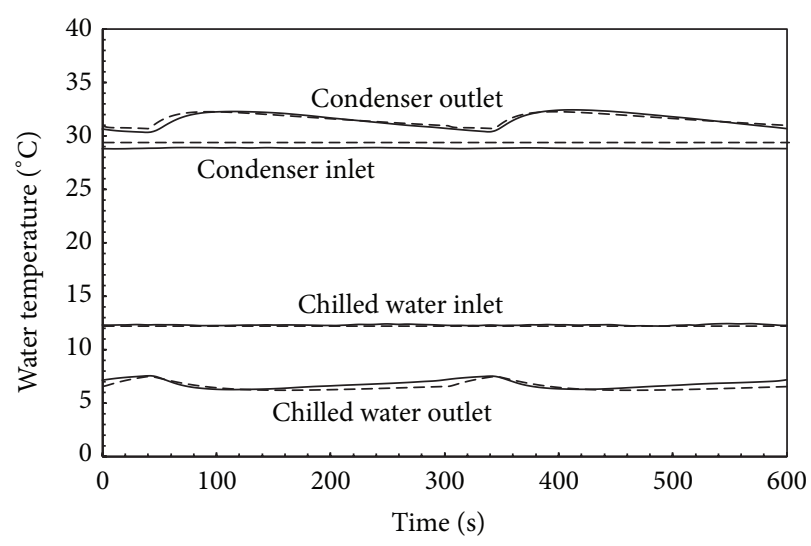

Figure 4: A comparison of temperature histories at condenser and evaporator outlets between experiment and simulations. - : experimental data; - - -: simulation results.

simply affects the hot water circulation external to the chiller system, it does not affect the cooling capacity as shown in Figure 5, which is why only one set of cooling capacity curves are presented. However, it substantially reduces the thermal energy consumption at the hot water reservoir and hence markedly improves the system COP as presented in Figure 6 . At the rated condition where $T_{\text {chilled }}^{\text {out }}=12.2^{\circ} \mathrm{C}, T_{\text {hot }}^{\text {in }}=$ $85^{\circ} \mathrm{C}, T_{\text {cool }}^{\text {in }}=29.4^{\circ} \mathrm{C}$, and cycle time ranges from $120 \mathrm{~s}$ to $420 \mathrm{~s}$ which is the preferred cycle time for the four-bed adsorption chiller, the simulation can accurately predict the cooling capacity and COP to within $12.5 \%$. This proves that our kinetic model for the adsorption of water vapour is ostensibly adequate to describe the boiling phenomenon at the evaporator under the rated conditions and therefore for chiller design. Over all the cycle times, the passive heat recovery scheme can boost the system COP by up to $25 \%$.

The performance predictions at lower hot water temperatures are shown in Figures 7 and 8. Figure 7 depicts the cooling capacity versus cycle time at the hot water temperatures of $75^{\circ} \mathrm{C}$ and $65^{\circ} \mathrm{C}$, respectively, which confirms that we can accurately predict the cooling capacity at the 


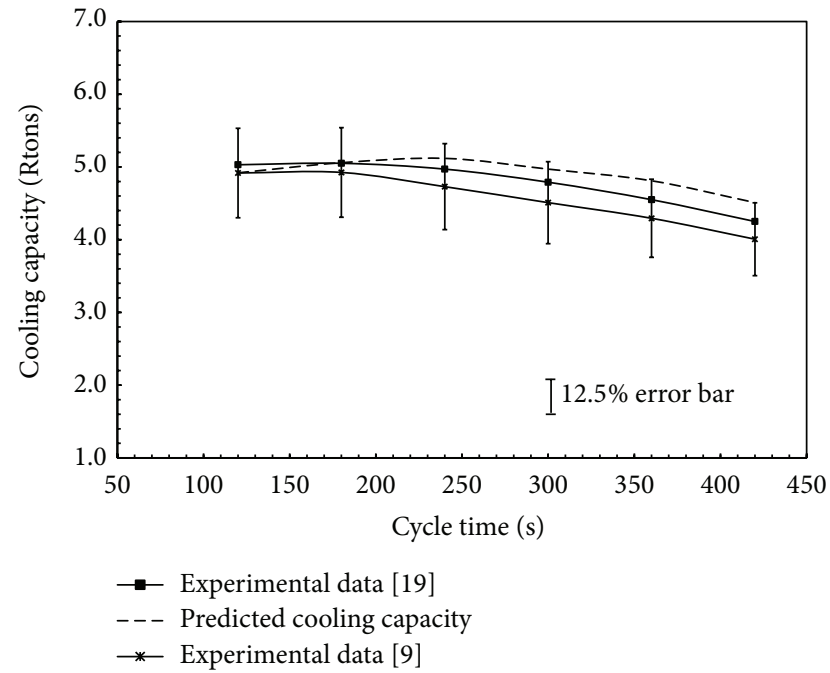

FIgURE 5: Predicted cooling capacity at ARI standard conditions (hot water temperature $85^{\circ} \mathrm{C}$, cooling water temperature $29.4^{\circ} \mathrm{C}$, and chilled water temperature $12.2^{\circ} \mathrm{C}$ ).

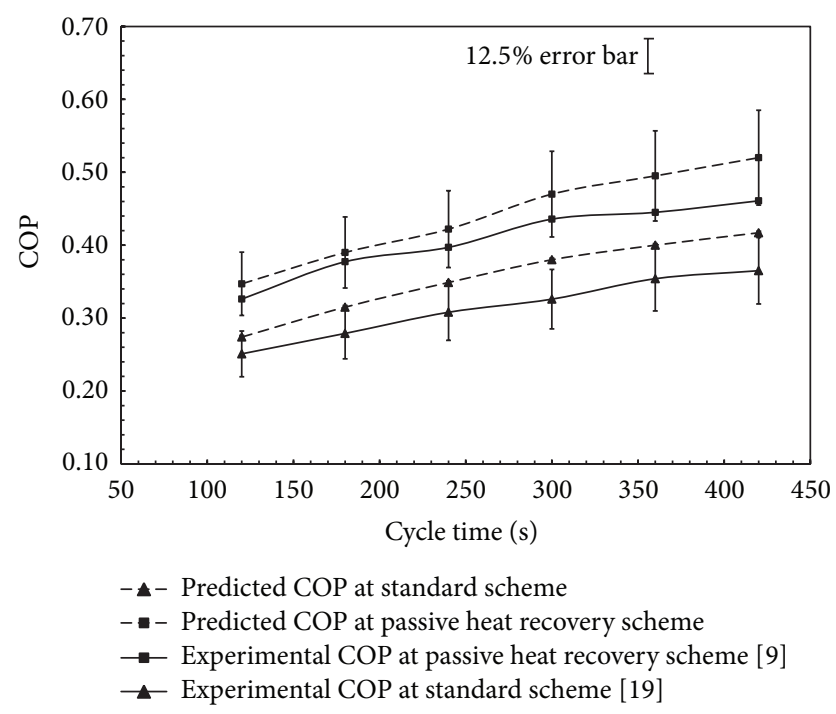

FIgURE 6: Predicted COP at ARI standard working conditions (hot water temperature $85^{\circ} \mathrm{C}$, cooling water temperature $29.4^{\circ} \mathrm{C}$, and chilled water temperature $12.2^{\circ} \mathrm{C}$ ).

part-load conditions as well. However, with decreasing hot water temperature, the prediction error gets slightly bigger. This is likely due to the idiosyncrasy of evaporator performance under off-rated conditions [23]. Figure 8 shows the favourable predictive capability of our model for the COP at hot water temperatures of $75^{\circ} \mathrm{C}$ and $65^{\circ} \mathrm{C}$, respectively. It highlights that the prediction error increases with decreasing hot water temperature. This may be due to our assumption of a constant isosteric heat, which stems from the Tóth isotherm fitting of the silica gel-water experimental data. In reality, we believe the isosteric heat is actually dependent

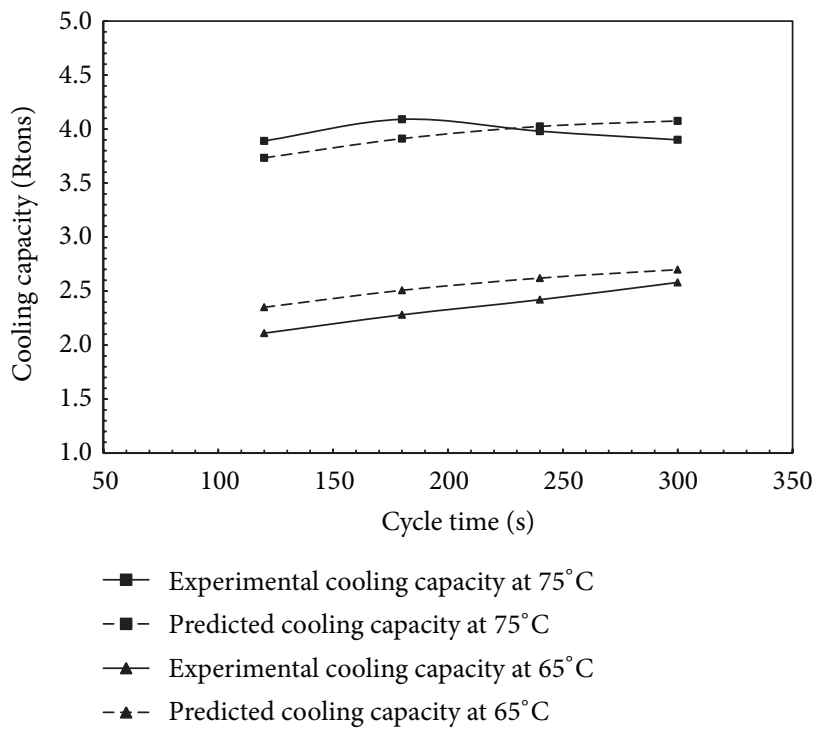

FIGURE 7: Predicted cooling capacity at hot water temperatures $75^{\circ} \mathrm{C}$ and $65^{\circ} \mathrm{C}$, respectively (cooling water temperature $29.4^{\circ} \mathrm{C}$ and chilled water temperature $\left.12.2^{\circ} \mathrm{C}\right)$.

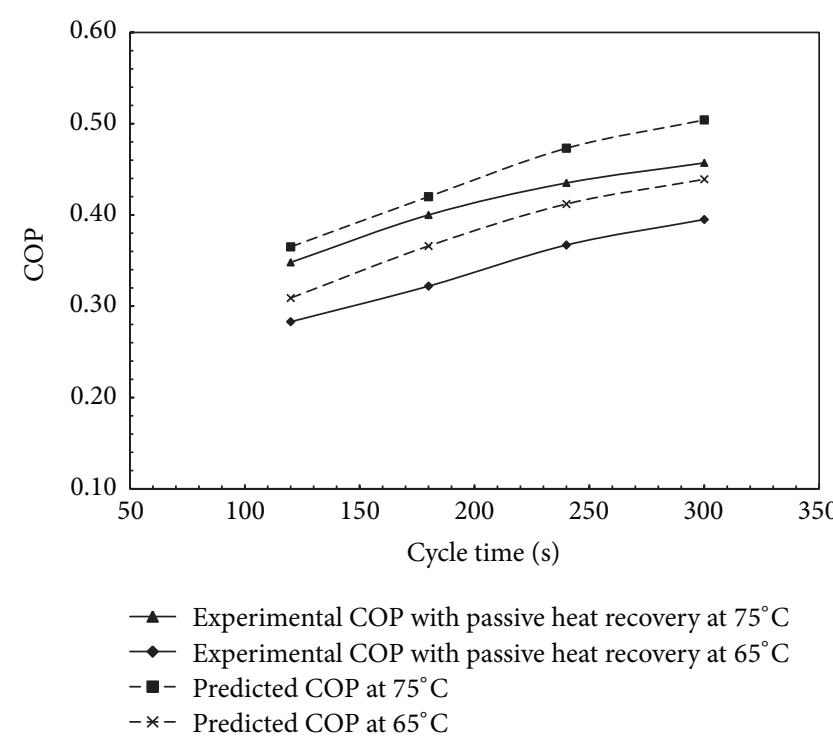

Figure 8: Predicted COP at hot water temperatures $75^{\circ} \mathrm{C}$ and $65^{\circ} \mathrm{C}$, respectively (cooling water temperature $29.4^{\circ} \mathrm{C}$ and chilled water temperature $\left.12.2^{\circ} \mathrm{C}\right)$.

on the adsorption temperature but is currently hard to be determined quantitatively $[24,25]$.

\section{Conclusions}

A facile and reliable lump-parameter model for a four-bed adsorption chiller with the passive heat recovery has been developed. Our predictive results compare favourably with experimental results, over an assortment of operating conditions. The performance of a previously reported passive heat 
recovery scheme, which substantially boosts the system COP, can also be favourably predicted by this lump-parameter model. It is concluded that our improved lump-parameter model adequately captures the characteristics of the four-bed adsorption chiller with the passive heat recovery scheme. Our model will provide manufacturers with useful information for the design of four-bed adsorption chillers.

\section{Nomenclature}

\begin{tabular}{|c|c|}
\hline A: & Heat transfer area $\left(\mathrm{m}^{2}\right)$ \\
\hline COP: & Coefficient of performance \\
\hline$c_{v}:$ & Specific heat capacity $(\mathrm{J} / \mathrm{kg} \cdot \mathrm{K})$ \\
\hline$D_{s o}:$ & Preexponent constant $\left(\mathrm{m}^{2} / \mathrm{s}\right)$ \\
\hline$E_{a}:$ & $\begin{array}{l}\text { Activation energy of surface } \\
\text { diffusion }(\mathrm{kJ} / \mathrm{kg})\end{array}$ \\
\hline$h:$ & Enthalpy $(\mathrm{J} / \mathrm{kg})$ \\
\hline$\hbar:$ & Heat transfer coefficient $\left(\mathrm{W} / \mathrm{m}^{2} \cdot \mathrm{K}\right)$ \\
\hline$k:$ & Thermal conductivity $(\mathrm{W} / \mathrm{m} \cdot \mathrm{K})$ \\
\hline$M:$ & Mass $(\mathrm{kg})$ \\
\hline$N:$ & $\begin{array}{l}\text { Number of discrete elements in the heat } \\
\text { exchanging tubes of the beds }\end{array}$ \\
\hline$N_{1}:$ & $\begin{array}{l}\text { Number of discrete elements in the heat } \\
\text { exchanging tubes of the evaporator }\end{array}$ \\
\hline$N_{2}:$ & $\begin{array}{l}\text { Number of discrete elements in the heat } \\
\text { exchanging tubes of the condenser }\end{array}$ \\
\hline$N_{\text {tube }}:$ & $\begin{array}{l}\text { Number of discrete elements in the } \\
\text { connecting pipes }\end{array}$ \\
\hline$P:$ & Pressure $(\mathrm{Pa})$ \\
\hline$q:$ & $\begin{array}{l}\text { Fraction of refrigerant as adsorbed by } \\
\text { the adsorbent ( } \mathrm{kg} / \mathrm{kg} \text { dry adsorbent) }\end{array}$ \\
\hline$q^{*}:$ & $\begin{array}{l}\text { Fraction of refrigerant which } \\
\text { can be adsorbed by the adsorbent } \\
\text { under saturation condition } \\
\text { (kg/kg dry adsorbent) }\end{array}$ \\
\hline$Q_{\text {evap }}:$ & Cycle average cooling capacity (W) \\
\hline$R:$ & Universal gas constant $(\mathrm{J} / \mathrm{mol} \cdot \mathrm{K})$ \\
\hline$R_{p}:$ & Average radius of silica gel (m) \\
\hline$t:$ & Time (s) \\
\hline$t_{\text {cycle }}:$ & Cycle time (s) \\
\hline$T:$ & Temperature $\left({ }^{\circ} \mathrm{C}\right)$ \\
\hline$U_{\text {chilled }}$ : & $\begin{array}{l}\text { Heat transfer coefficient of } \\
\text { the evaporator }\left(\mathrm{W} / \mathrm{m}^{2} \cdot \mathrm{K}\right)\end{array}$ \\
\hline$U_{\text {cond }}:$ & $\begin{array}{l}\text { Heat transfer coefficient of } \\
\text { the condenser }\left(\mathrm{W} / \mathrm{m}^{2} \cdot \mathrm{K}\right)\end{array}$ \\
\hline$U_{c}:$ & $\begin{array}{l}\text { Heat transfer coefficient of } \\
\text { the adsorber }\left(\mathrm{W} / \mathrm{m}^{2} \cdot \mathrm{K}\right)\end{array}$ \\
\hline$U_{h}:$ & $\begin{array}{l}\text { Heat transfer coefficient of } \\
\text { the desorber }\left(\mathrm{W} / \mathrm{m}^{2} \cdot \mathrm{K}\right)\end{array}$ \\
\hline$V:$ & $\begin{array}{l}\text { Internal volume of heat exchanger } \\
\text { tubes }\left(\mathrm{m}^{3}\right)\end{array}$ \\
\hline$\dot{m}:$ & Flow rate $(\mathrm{kg} / \mathrm{s})$ \\
\hline$\Delta H_{\text {ads }}:$ & Isosteric heat of adsorption $(\mathrm{J} / \mathrm{kg})$ \\
\hline$\delta:$ & $\begin{array}{l}\text { Flag that governs connecting } \\
\text { pipe transients }\end{array}$ \\
\hline$\zeta:$ & Flag that governs adsorber transients \\
\hline$\gamma:$ & Flag that governs evaporator transients \\
\hline$\theta:$ & Flag that governs condenser transients \\
\hline$\rho:$ & Density $\left(\mathrm{kg} / \mathrm{m}^{3}\right)$ \\
\hline
\end{tabular}

Superscripts/Subscripts

$\begin{array}{ll}\text { air: } & \text { Air } \\ \text { ads: } & \text { Adsorption } \\ \text { bed: } & \text { Adsorption or desorption bed } \\ \text { chilled: } & \text { Chilled water } \\ \text { cond: } & \text { Condenser or condenser cooling water } \\ \text { cool: } & \text { Cooling water or bed cooling water } \\ \text { cycle: } & \text { Cycle } \\ \text { evap: } & \text { Evaporator or chilled water } \\ f: & \text { Fluid (liquid water) } \\ g: & \text { Gaseous water } \\ \text { hot: } & \text { Hot water or heating } \\ \text { Hex: } & \text { Heat exchanger tube-fin assembly } \\ i: & \text { Adsorber } \\ \text { in: } & \text { Inlet } \\ j: & \text { Desorber } \\ k: & \text { Discrete element } \\ m: & \text { Metal tube or water in } \\ \text { pm,hot: } & \text { Metal tube between desorber outlet } \\ \text { pm,cool: } & \text { Metal tube between adsorber outlet } \\ & \text { and system outlet } \\ \text { out: } & \text { Outlet } \\ \text { p-a: } & \text { Precooling } \\ \text { p-h: } & \text { Preheating } \\ \text { rec: } & \text { Recovery } \\ \text { ref: } & \text { Reference } \\ \text { rej: } & \text { Rejected energy } \\ \text { sat: } & \text { Saturated } \\ \text { sg: } & \text { Silica gel. } \\ & \end{array}$

\section{Conflict of Interests}

The authors declare that there is no conflict of interests regarding the publication of this paper.

\section{References}

[1] Y. Yonezawa, M. Matsushita, K. Oku et al., "Adsorption refrigeration system," U.S. Patent no. 4881376, 1989.

[2] H. T. Chua, K. C. Ng, A. Malek, T. Kashiwagi, A. Akisawa, and B. B. Saha, "Modeling the performance of two-bed, silica gel-water adsorption chillers," International Journal of Refrigeration, vol. 22, no. 3, pp. 194-204, 1999.

[3] C. Hildbrand, P. Dind, M. Pons, and F. Buchter, "A new solar powered adsorption refrigerator with high performance," Solar Energy, vol. 77, no. 3, pp. 311-318, 2004.

[4] X. Q. Zhai and R. Z. Wang, "Experimental investigation and performance analysis on a solar adsorption cooling system with/without heat storage," Applied Energy, vol. 87, no. 3, pp. 824-835, 2010.

[5] K. C. Ng, H. T. Chua, J. Wang, and X. Wang, "Experimental Investigation on a novel four-bed adsorption chiller," Transactions of the JSRAE, vol. 20, no. 3, pp. 429-435, 2003.

[6] Y. L. Liu, R. Z. Wang, and Z. Z. Xia, "Experimental performance of a silica gel-water adsorption chiller," Applied Thermal Engineering, vol. 25, no. 2-3, pp. 359-375, 2005. 
[7] A. R. M. Rezk and R. K. Al-Dadah, "Physical and operating conditions effects on silica gel/water adsorption chiller performance," Applied Energy, vol. 89, no. 1, pp. 142-149, 2012.

[8] H. Luo, R. Wang, and Y. Dai, "The effects of operation parameter on the performance of a solar-powered adsorption chiller," Applied Energy, vol. 87, no. 10, pp. 3018-3022, 2010.

[9] K. C. Ng, X. Wang, Y. S. Lim et al., "Experimental study on performance improvement of a four-bed adsorption chiller by using heat and mass recovery," International Journal of Heat and Mass Transfer, vol. 49, no. 19-20, pp. 3343-3348, 2006.

[10] E. Voyiatzis, J. A. Palyvos, and N.-C. Markatos, "Heat-exchanger design and switching-frequency effects on the performance of a continuous type solar adsorption chiller," Applied Energy, vol. 85, no. 12, pp. 1237-1250, 2008.

[11] H. T. Chua, K. C. Ng, W. Wang, C. Yap, and X. L. Wang, "Transient modeling of a two-bed silica gel-water adsorption chiller," International Journal of Heat and Mass Transfer, vol. 47, no. 4, pp. 659-669, 2004.

[12] GBU mbH, Germany, Adsorption chiller NAK, http://www .adsorption.de.

[13] B. B. Saha, E. C. Boelman, and T. Kashiwagi, "Computational analysis of an advanced adsorption-refrigeration cycle," Energy, vol. 20, no. 10, pp. 983-994, 1995.

[14] H. T. Chua, K. C. Ng, A. Malek, T. Kashiwagi, A. Akisawa, and B. B. Saha, "Multi-bed regenerative adsorption chiller-improving the utilization of waste heat and reducing the chilled water outlet temperature fluctuation," International Journal of Refrigeration, vol. 24, no. 2, pp. 124-136, 2001.

[15] R. Z. Wang, "Performance improvement of adsorption cooling by heat and mass recovery operation," International Journal of Refrigeration, vol. 24, no. 7, pp. 602-611, 2001.

[16] T. F. Qu, R. Z. Wang, and W. Wang, "Study on heat and mass recovery in adsorption refrigeration cycles," Applied Thermal Engineering, vol. 21, no. 4, pp. 439-452, 2001.

[17] A. Akahira, K. C. A. Alam, Y. Hamamoto, A. Akisawa, and T. Kashiwagi, "Mass recovery adsorption refrigeration cycleimproving cooling capicity," International Journal of Refrigeration, vol. 27, no. 3, pp. 225-234, 2004.

[18] X. Wang and H. T. Chua, "A comparative evaluation of two different heat-recovery schemes as applied to a two-bed adsorption chiller," International Journal of Heat and Mass Transfer, vol. 50, no. 3-4, pp. 433-443, 2007.

[19] X. Wang, H. T. Chua, and K. C. Ng, "Experimental investigation of silica gel-water adsorption chillers with and without a passive heat recovery scheme," International Journal of Refrigeration, vol. 28, no. 5, pp. 756-765, 2005.

[20] K. Chihara and M. Suzuki, "Air drying by pressure swing adsorption," Journal of Chemical Engineering of Japan, vol. 16, no. 4, pp. 293-299, 1983.

[21] X. Wang and H. T. Chua, "Two bed silica gel-water adsorption chillers: An effectual lumped parameter model," International Journal of Refrigeration, vol. 30, no. 8, pp. 1417-1426, 2007.

[22] NACC, PTX Data for the Silica Gel-Water Pair, Manufacturer's Proprietary Data, Nishiyodo Air Conditioner Company, Tokyo, Japan, 1992.

[23] N. K. Choon, A. Chakraborty, S. M. Aye, and W. Xiaolin, "New pool boiling data for water with copper-foam metal at subatmospheric pressures: experiments and correlation," Applied Thermal Engineering, vol. 26, no. 11-12, pp. 1286-1290, 2006.

[24] P. B. Whittaker, X. Wang, K. Regenauer-Lieb, and H. T. Chua, "Predicting isosteric heats for gas adsorption," Physical Chemistry Chemical Physics, vol. 15, no. 2, pp. 473-482, 2013.
[25] P. B. Whittaker, X. Wang, W. Zimmermann, K. Regenauer-Lieb, and H. T. Chua, "Predicting the integral heat of adsorption for gas physisorption on microporous and mesoporous adsorbents," The Journal of Physical Chemistry C, vol. 118, no. 16, pp. 8350-8358, 2014. 


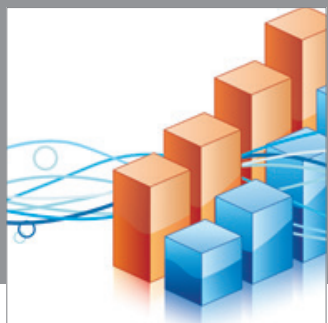

Advances in

Operations Research

mansans

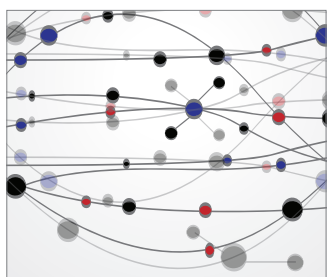

The Scientific World Journal
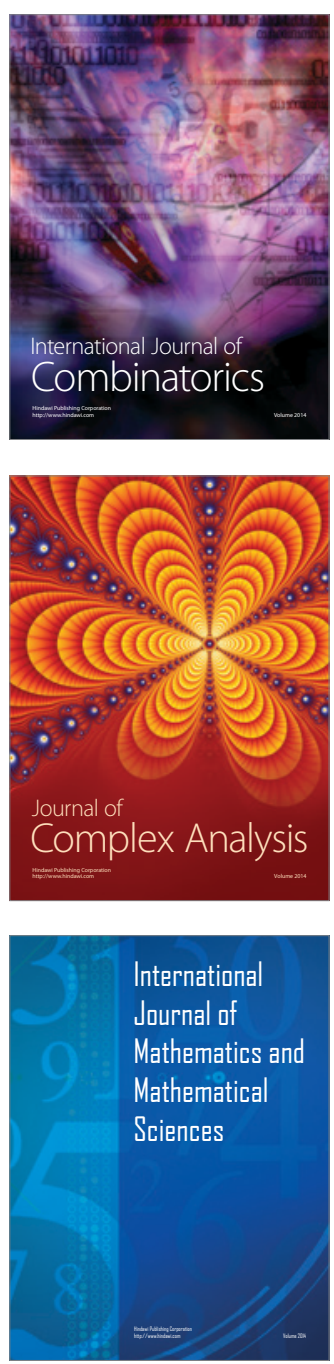
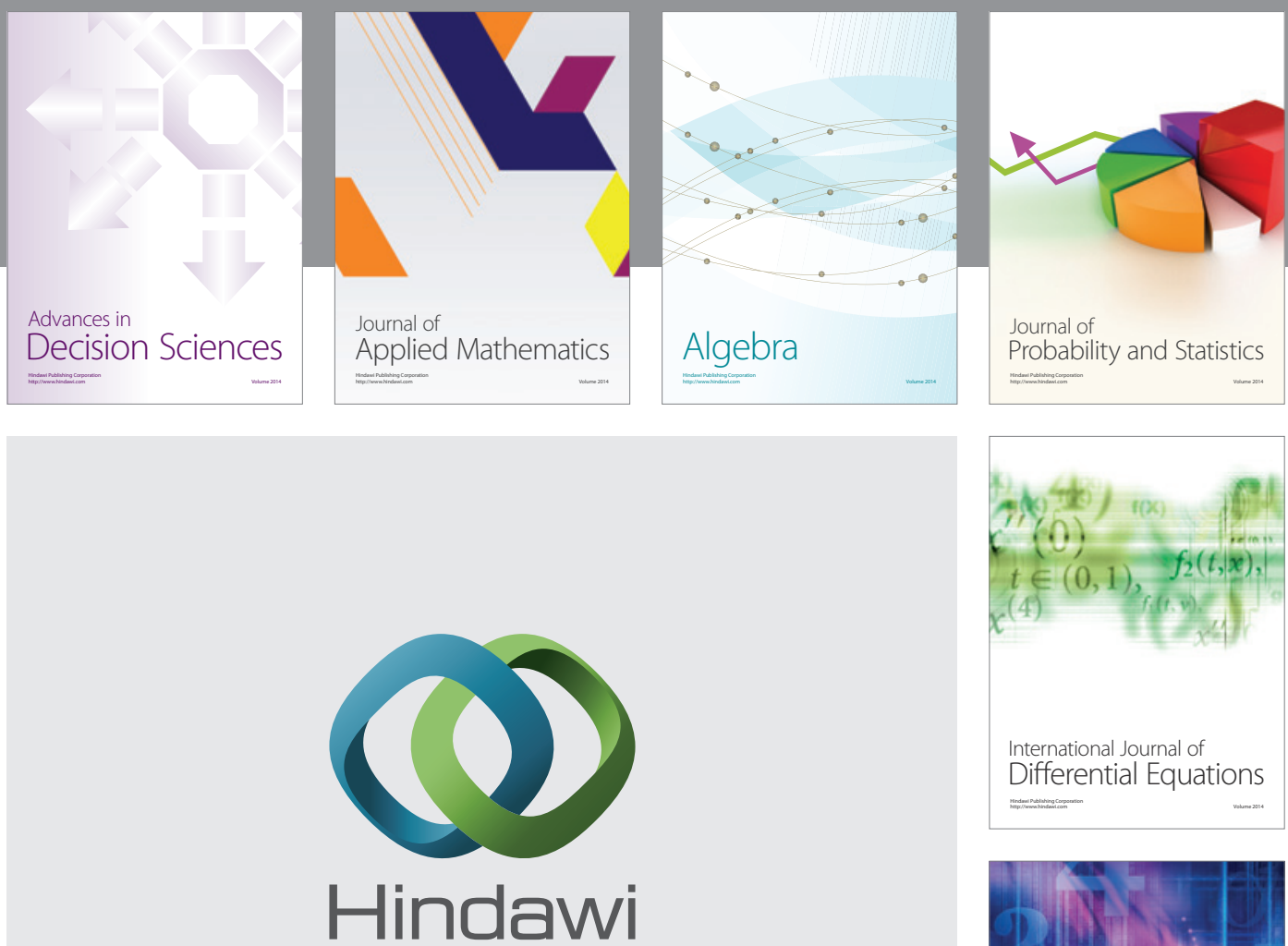

Submit your manuscripts at http://www.hindawi.com
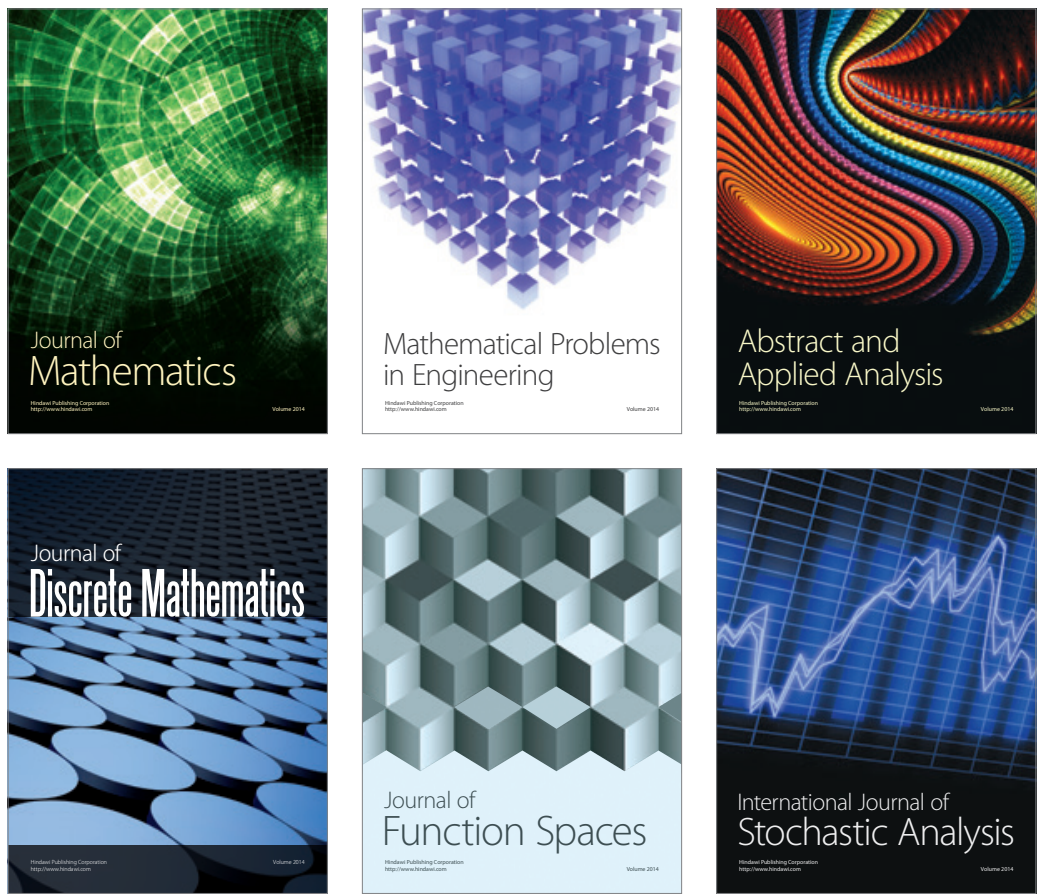

Journal of

Function Spaces

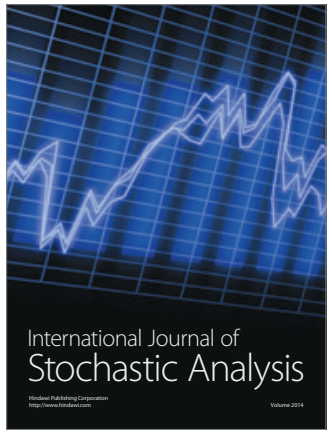

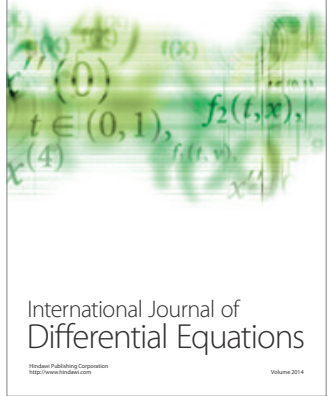
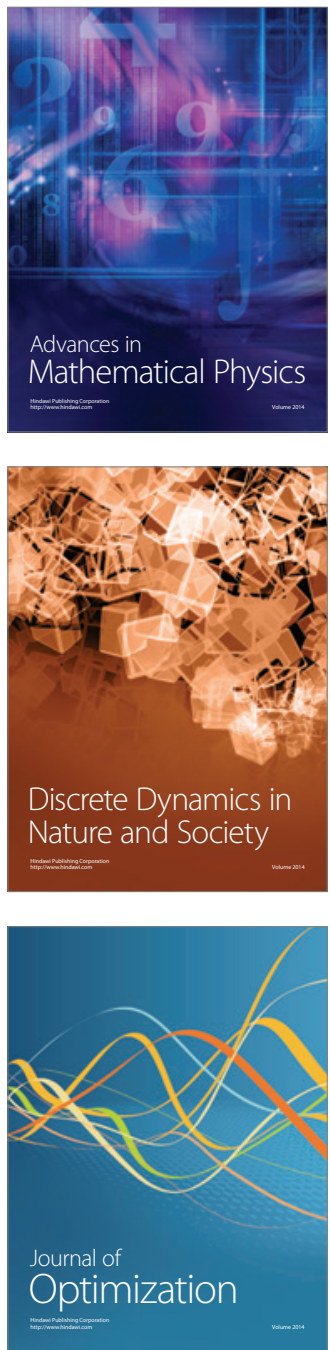